This is an Accepted Manuscript of an article published by Taylor \& Francis in Journal of Social Welfare and Family Law on 12-09-16, available online:

http://www.tandfonline.com/doi/abs/10.1080/09649069.2016.1228146 
TITLE PAGE

\title{
PATIENT NARRATIVE: AN 'ON-SWITCH’ FOR EVALUATING BEST INTERESTS
}

\section{Word Count 7197}

\author{
AUTHOR AFFILIATIONS \\ Dr Carolyn Johnston (corresponding author) \\ Adviser Medical Law \& Ethics, GKT School of Medical Education, Faculty of Life Sciences \\ \& Medicine, \\ King's College London, UK \\ and \\ Senior Lecturer, Kingston University, UK \\ 4.18 Shepherd's House \\ Guy's campus, London SE1 1UL \\ T: 02078486994 \\ E: Carolyn.johnston@kcl.ac.uk
}

Dr Natalie Banner

Independent researcher, formerly at King's College London ${ }^{1}$

E: n.banner@wellcome.ac.uk

Dr Angela Fenwick,

Associate Professor in Medical Ethics and Education,

Faculty of Medicine

\footnotetext{
${ }^{1}$ Currently Policy Officer and EAGDA Secretariat, Wellcome Trust, Gibbs Building, 215

Euston Road, London,NW1 2BE, UK
} 
University of Southampton

Room 4001 Building 85

Highfield campus, University Road,

Southampton

SO17 1BJ

E: A.J.Fenwick@soton.ac.uk

\section{ABSTRACT (153 WORDS)}

This article examines how the wishes, feelings, values and beliefs of adults lacking capacity can be evaluated and the extent to which they are given effect in best interests' decisionmaking. One way of fulfilling the clinician's legal responsibilities to take a patient's preferences into account is to explicitly link these to the notion of narrative. Narratives provide a compelling grounding and give weight to views and values that may have been informally and consistently expressed in the past. An evaluation of recent case law suggests that the trajectory of a person's life, their character and personality, and the perspectives of those with whom the patient has valued relationship are given increasing judicial recognition. Attending to the narrative of the patient could lead to a more sophisticated judgement of best interests than an objective 'balance sheet' approach would allow and enable greater alignment with the UN Convention on the Rights of Persons with Disabilities.

\section{KEYWORDS:}

Narrative, Best interests, mental capacity, healthcare decision-making 


\section{PATIENT NARRATIVE: AN ‘ON-SWITCH’ FOR EVALUATING BEST}

\section{INTERESTS}

\section{Introduction}

It is accepted that patients should be empowered and actively involved in their care, not merely passively receiving authoritative medical pronouncements on their diagnosis and treatment (Coulter and Collins 2011). Patient-centred approaches emphasise the importance of understanding patients' subjective expertise, emotions, history, well-being and lived experience as they negotiate the healthcare system. Unsurprisingly references to patients' perspectives tend to be raised in the context of patients who have the capacity to make decisions and are able to engage in a meaningful dialogue. However, the importance of the patient's perspective is increasingly recognised in respect of decisions made for patients who are unable to do so themselves (House of Lords Select Committee on the Mental Capacity Act 2005, post legislative scrutiny, 2014, Summary). The 'best interests' decision making process, as outlined in the Mental Capacity Act 2005 (MCA), aims to ensure that the wishes, feelings, values and beliefs of patients lacking capacity remain central to the decision being made. In the Supreme Court judgment in Aintree University Hospitals NHS Foundation Trust v James [2013] UKSC 67, Lady Hale confirmed that 'the purpose of the best interests test is to consider matters from the patient's point of view' (para 45).

Compliance with the UN Convention on the Rights of Persons with Disabilities (CRPD) requires states to "ensure that measures relating to the exercise of legal capacity respect the rights, will and preferences of the person' (Article 12(4)). A move away from an 'objective' assessment of a person's best interests, requiring greater emphasis on the role of the patient in the best interests' decision making process, achieves a closer alignment with the requirements 
of the CRPD. Nevertheless the House of Lords' post legislative scrutiny of the MCA found that best interests' decision making is often not undertaken in the way set out in the MCA, both because health and social care professionals are not aware of the requirements and because they find the core principles difficult to apply. The British Institute of Learning Disabilities in their evidence to the Committee reported that "all too often "best interests" is interpreted in a medical/paternalistic sense which is wholly at odds with that set out in the Act' (para 90).

This paper sets out to consider the following questions: what do the phrases 'past and present wishes and feelings' 'beliefs and values' and 'other factors' mean in the context of a clinical best interests decision; how can these be ascertained for an individual patient who lacks capacity; and to what extent should these be determinative? We argue that conceptualising the patient's wishes, feelings, beliefs and values in terms of a patient's narrative could provide more in-depth contextual information. It could also give clues as to the best ways to enable a meaningful re-focus of best interests' decision-making, moving from purely clinical judgments to the inclusion of values and interests of the patient to more truly reflect the principles outlined in the MCA.

\section{Wishes, feelings, beliefs and values}

In England and Wales the 'best interests' standard is used for decision making for adults who lack capacity. The MCA sets out a checklist of factors that must be considered in deciding what is in the best interests of a person who lacks capacity with regard to a particular decision. Alongside the medically ascertainable facts and the patient's clinical needs, the decision maker is required to consider, so far as they are 'reasonably ascertainable': 
a) the person's past and present wishes and feelings (and, in particular, any relevant written statement made by him when he had capacity)

b) the beliefs and values that would be likely to influence his decision if he had capacity, and

c) other factors that he would be likely to consider if he were able to do so (s4 (6)).

The MCA Code of Practice gives some guidance as to what these phrases might encompass. Wishes and feelings might be revealed by a patient through their 'emotional responses' (para 5.40). The previously held views of the patient might impact on the decision to be made. Evidence of a person's beliefs and values can be found in their 'cultural background, religious beliefs, political convictions and past behaviors or habits' (para 5.46). 'Other factors' which may be taken into account appear to reflect an acknowledgement of the patient's social world so can include 'effect of the decision on other people, obligations to dependents or the duties of a responsible citizen' (para 5.47). In the Matter of G(TJ) [2010] EWHC 3005 (COP) Morgan J. stated that the court is not confined to considering the selfinterest of the patient - his wishes which are altruistic and not in any way, directly or indirectly self-interested, can be a relevant factor (para 56). So a decision that benefits others is permissible but must also be in the best interests of the patient.

The patient's wishes, feelings, beliefs and values are important constituent elements in assessing a patient's best interests. This is clearly evident in cases such as United Lincolnshire Hospitals NHS Trust v N [2014] EWCOP 16 and St George's Healthcare NHS Trust v P [2015] EWCOP 42. However, Hayden J in Sheffield Teaching Hospitals NHS Foundation Trust $v$ TH [2014] EWCOP 4 stated that a patient's prior wishes are not synonymous with their best interests: "wishes" and "best interests" should never be conflated, they are entirely separate matters which may ultimately weigh on different sides of 
the balance sheet' (para 56). Whilst the assessment of a patient's best interests involves an element of substituted judgment, the patient's previously expressed wishes are not determinative.

\section{As Lady Hale stated in Aintree,}

the purpose of the best interests test is to consider matters from the patient's point of view. That is not to say that his wishes must prevail, any more than those of a fully capable patient must prevail. We cannot always have what we want' (Aintree University Hospitals NHS Foundation Trust v James, Lady Hale, para 45)

Constructing a balance sheet of burdens and benefits which draws on both medical and personal information is not straightforward as acknowledged by the Aintree Supreme Court judgement:

The most that can be said, therefore, is that in considering the best interests of this particular patient at this particular time, decision-makers must look at his welfare in the widest sense, not just medical but social and psychological; they must consider the nature of the medical treatment in question, what it involves and its prospects of success; they must consider what the outcome of that treatment for the patient is likely to be; they must try and put themselves in the place of the individual patient and ask what his attitude to the treatment is or would be likely to be; and they must consult others who are looking after him or interested in his welfare, in particular for their view of what his attitude would be (para 39, per Lady Hale).

How, though, can health care professionals, whose expertise is in assessing medical best interests, evidence a patient's wishes, feelings, beliefs and values (as well as other factors) when a patient is in a state of incapacity? Advance decisions and statements provide some 
sorts of evidence but not everyone states or records their wishes in advance. Drawing on narrative approaches to medicine could provide us with useful insights into how and what to try to access.

\section{Drawing on narrative approaches}

The emergence of 'narrative medicine' as a tool for clinical practice suggests that the emphasis on meaningful communication, understanding and dialogue between clinician and patient is an increasingly important competency for healthcare professionals (Greenhalgh \& Hurwitz 1999). It is based on the assumption that clinicians need to listen to, and seek to understand, the stories of their patients with the aim of providing more compassionate, humane and appropriate care (Charon 2004). However, such approaches have been concerned exclusively with the possibilities of developing a fruitful collaboration between

clinician and patient and thus require at least a basic level of current and on-going engagement and communication. To establish the extent to which narrative medicine can help to ascertain a patient's wishes, feelings, beliefs and values when making decisions on their behalf when they lack the capacity it is useful to explore the concept further.

Theories of narrative identity are complex and often controversial - which we return to later but here a non-technical definition will suffice: we wish to consider narrative an instantiation of the beliefs, values, experiences, actions, decisions, events and relationships that give meaning and coherence to a person's life. Three particular features of a narrative identity are pertinent to our discussion of the potential that narrative has to play in healthcare decisionmaking. 
Firstly, narratives give expression to a person's deeply held values. Values concern the kind of person one is, the sorts of things that are important to one. These can be highly specific, for example, adhering to a vegan diet, or more general, for example, a leaning towards political liberalism. In some cases, awareness of a patient's value system clearly prescribes how a patient ought to be treated and provides insight into their wishes: it is justifiable for clinicians to not provide a blood transfusion to a committed and practising Jehovah's Witness, for example. Other healthcare related values may also dictate the patient's wishes explicitly, for example by being on the organ donor register.

However, not all values guide or direct action so prescriptively. A common value expressed by individuals who witness the decline and mental deterioration of elderly relatives is the desire for dignity towards the end of life, something that many often do not see as compatible with living in a nursing home, being incontinent and requiring assistance with personal care. What this reflects is something about the kind of person one is, what one values, and how one wishes to live one's life. Such values may also provide insight into what would give a person a good death. Such expressions do not provide evidence for particular healthcare/end of life choices in specific (usually unforeseeable) circumstances, but they do provide a rich seam of context in which to make some judgement about what kinds of treatment, or non-treatment, the person would likely want in a given situation. The extent to which these appear coherent expressions of value within a person's life can give them weight and significance. They are not individual preferences specific to particular circumstances but general, broad instantiations of the kind of person one is and wants to be, with or without capacity.

A second pertinent feature of narratives is that they are not snap-shots or time-slices of a person's psychology at a particular moment in time. They are not temporally isolated; rather 
they bind successive events together in a meaningful way, projecting backwards into the past, making sense of previous experiences, events and relationships, and they anchor oneself in the present. Furthermore, and importantly for our discussion, they project into the future; for example aspiring towards a particular career or getting married with the anticipation of starting - or not having - a family, or even planning for one's death. This temporal nature also serves a powerful explanatory function, not only for the purposes of accounting for, or explaining, past actions and events, but for making claims about, and giving shape to, the future. In representing and explaining the past and present, a narrative may form expectations about future events (Teichert 2004, p. 183) and what a person is likely to want or do in the future, even if these are not specifically attuned to the particular circumstances that person finds herself in. Whilst some have argued that a person who lacks capacity may have different interests from when they had capacity or, in some circumstances (such as patients with dementia) may be viewed as a different person (see for example Dresser, 1995), here we are interested in how best to meet to requirements of the Mental Capacity Act in the assessment of best interests.

Thirdly, a narrative is not created in isolation from other people: the people with whom one has relationships and interactions are crucial in enabling one's narrative to be fulfilled, enacted or otherwise realised. There is much debate about whether or not other people can actually constitute a person's narrative where the person themselves ceases to be able to give full expression to it, as in cases of advancing dementia, (Radden and Fordyce 2006, Ch.5) but it is not necessary to explore this ontological position here: what matters to the notion of narrative is that it is essentially bound up with other people, supported or marginalised by those around us. Our significant others can help us give full expression to who we are and 
what we want, or undermine it through not hearing, not respecting or dismissing what is meaningful and significant to us.

Narrative approaches have been used to understand the patient's experience of illness and to provide insights into this experience in the context of patient's with capacity. They have been criticised for being too trusting of people's own accounts of their illness and for overemphasising their importance. Strawson (2004), however, questions the very notion that we live our lives like a story - with a beginning and end with a past and a future - and asserts that that there is nothing wrong with living a 'non-Narrative' life, being a nonNarrative person, where one's self is not conceived as coherent or existing through time. Moreover, Woods (2011) cautions against a narrative approach that, whilst professing to be universally applicable, is in fact euro-centric. She cites the work of Carel (2012) and others who explore alternative ways that patients can explore the meaning of their experiences that do not require story telling; for example through the use of phenomenology, metaphor or photography.

Strawson and Wood's work are useful reminders to question the notion of a person's life as a continuing story neatly articulated; however, we argue that the three aspects of narrative we outline are pertinent, providing insight into understanding what might constitute a patient's wishes, feelings, beliefs and values when they lack capacity. A review of how recent court judgements have drawn on aspects of a patient's narrative to construct a balance sheet might give health care professionals confidence in the role that this can play in making decisions on behalf of patients who lack capacity; however, we start with a discussion of a case in which these insights did not come into play: $R e M$. 


\section{$\operatorname{Re} M$ : significant weight to preservation of life}

The case of $W v M$ [2011] EWHC 2443 (Fam) provides a useful starting point in considering the weight attributed to the patient's prior expressions. M, a previously active and independent woman in her 40s was left in minimally conscious state following a sudden collapse as a result of contracting viral encephalitis. Despite evidence from the woman's sister and her partner that she would be horrified to be living in such an undignified manner (paragraph 119), Baker J. thought it would be wrong to attach significant weight to these statements, made before her collapse, because there was no evidence that $\mathrm{M}$ 'ever specifically considered the question of withdrawal of ANH [artificial nutrition and hydration], or ever considered the question whether she would wish such treatment to be withdrawn if in a minimally conscious state' (paragraph 230). Even if $M$ had considered these issues 'there is no way of knowing her current views, having lived in that state for over eight years' (paragraph 230). The judge accorded significant weight in the balance sheet to preservation of life and declared that withdrawal of artificial nutrition and hydration was not in M's best interests. Decisions were made as if $\mathrm{M}$ were any other person with the constellation of those clinical experiences. Indeed one of the experts called to give evidence to the court, a consultant and former neurosurgeon, expressed the view that $\mathrm{ANH}$ should never be withdrawn from a patient in a minimally conscious state (paragraph 198). Not surprisingly there has been criticism that the judgment in $\operatorname{Re} M$ is incompatible with the legal requirement to respect the past wishes of incompetent people' (Mullock 2013 p. 554).

What does this case indicate about the possible use of the notion of narrative to support best interests' decision-making? The three aspects of narrative sketched above can be illustrative here: firstly, M's prior expressions were deemed not sufficiently specified to carry evidential weight in the judgement. Where there is no written advance refusal of treatment or advance 
care plan the patient's prior views are inevitably piecemeal. However, in the absence of experience or anticipation of illness, $M$ nevertheless had indicated her views about dignity, dependence and what she felt was an acceptable quality of life. Thinking more broadly about a patient's narrative can combat the assumption that written, recorded, witnessed statements of explicit preference under a particular set of circumstances are required in order to know anything at all about what the patient would likely want.

Secondly, the kind of person $\mathrm{M}$ was prior to her accident did, intuitively for her family and loved ones, count for something in considering what she might want in these unforeseen circumstances. The kind of person she was and who she wanted to be mattered deeply to their consideration of what they thought would be in her best interests, and what she would have wanted given her current predicament. The idea of narrative as projecting into the future resonates here, although as Strawson (2004) reminds us, the idea of narrative as linear is limiting. The experience of illness, pain and dying can jolt on-going narrative identity, and values may change in light of new circumstances; this should make us cautious not to imply that the indications of a prior narrative ought in any way to trump other considerations. However, as an evidentiary background outlining why a person's past wishes and feelings bear relevance to the current decision at hand, the notion of narrative encapsulates what is epistemically important: that who a person was is meaningful and significant in understanding who they are now and deciding how they should be treated.

Finally, M's family provided a coherent, consistent picture of M's life, her values and broad wishes that were relevant to the situation she was now in. It is often difficult in practice to say what a patient would have wanted in the circumstances in which they now find themselves, because, as previously outlined, it is unlikely that they would ever have specifically 
articulated their wishes and preferences for those precise circumstances. As Kuczewski points out 'it is likely that many people are not the kind of persons who will know far in advance exactly what he/she will want in new and strange situations' (Kuczewski, 1999, p. 34). Indeed this is one of the difficulties of writing advance decisions where the bar for validity requires a high level of specificity. Nevertheless, expressions of a persons' narrative may be evidenced through the testimony of friends and family, drawing on things the patient previously said or did, and any current wishes those who are close to the patient are able to interpret as small indications of basic preferences.

\section{Increasing judicial account of narrative in best interests' decision making}

Whilst in $\operatorname{Re} M$ the judge indicated the need for a high level of specificity of prior views and beliefs in assessing her best interests, subsequent cases have indicated an increasing recognition by the judiciary that a patient's wider life story plays a valuable constitutive element in best interests' decision making. Patient narrative has been accepted as relevant when expressed in a wide variety of contexts, including: broad verbal statements which might have relevance to the current situation the patient finds herself in; evidence of character, indicating the patient's attitude to how they would wish to be treated; and wider interpretations of the sort of person the patient was and how they would thus likely respond to current treatments.

Judges have taken into account evidence from family and friends about the private nature of the patient and therefore the distress of being subject to ongoing treatment. In $\operatorname{Re} D$ [2012] EWHC 885 (COP) the judge focussed on what the patient was like, his characteristics and the way he lived his life previously, in order to gain a broader understanding about what treatment option would now be in his best interests. Peter Jackson J. acknowledged that 'D 
was a very private man before his incapacity' and drew the conclusions from the nature of the person D was, as articulated by his family: that he 'would have been horrified at the prospect of being kept alive in this condition with the total loss of privacy that his dependency entails' (paragraph 17).

In the case of Aintree $v$ James the relevance of the history of the patient and the type of characteristics he had displayed before loss of capacity was considered throughout the court hierarchy. In the High Court, Peter Jackson J. referred to the sentiment of DJ's wife (MJ) that the manner in which he had fought cancer 10 years previously gave an indication of the way he would now wish to receive treatment to keep him alive. MJ felt that DJ's experience of cancer threw light on his values and wishes in the current situation. It had been a very rough time, but he had told her 'this will not beat me'. The family believed that he would have the same attitude in his current predicament (NHS Trust v DJ [2012] EWHC 3524 (COP) paragraph 67).

Aintree $v$ James marks a high watermark in the importance of the patient's wishes, feelings values and beliefs informing best interests. In the Court of Appeal, Laws L.J., referred specifically to 'bios' - life as lived, and Dworkin's concept of the "actions, decisions, motives and events that compose what we now call a biography" (Aintree NHS Trust v David James [2013] EWCA Civ 65 paragraph 48). Laws L.J. (quoting Smith 2012 p. 319) noted that the ways in which we use our lives provide additional value to our mere existence and the biographical aspects of our lives have value and meaning and can be as important as, and sometimes even more important than, the fact of our existence. In the Supreme Court Lady Hale argued that the patient's ascertainable wishes, feelings, beliefs and values and the things 
which are important to him, should be taken into account because 'they are a component in making the choice which is right for him as an individual human being'(paragraph 45).

Subsequently, a number of cases indicate increasing judicial recognition of, and reliance on, evidence of the broad characteristics of the patient prior to loss of capacity in assessing his best interests. In United Lincolnshire Hospitals NHS Trust v N [2014] EWCOP 16, Pauffley J. took account of the type of person $\mathrm{N}$ (a woman in her fifties in minimally conscious state) was, through testimony of her former husband, adult daughter and cousin $(\mathrm{C})$, in determining N's best interests. The judge considered it relevant that $\mathrm{N}$ had always been a very private person and that she had never enjoyed being touched and so $\mathrm{C}$ thought that 'the necessity of

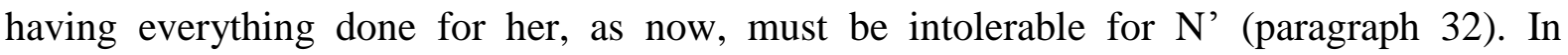
Sheffield Teaching Hospitals NHS Foundation Trust v TH [2014] EWCOP 4 TH, a man in his fifties in minimally conscious state, fed through naso-gastric tube, was described by friends and a former wife and long term partner as a very private, non-tactile person. Thus he would find 'abhorrent' the thought of being dependent on other people to clean and feed him. His friends said the fact that $\mathrm{TH}$ had a dislike of authority which extended to hospitals and 'medics of any description however well meaning' (para 41) would mean that his present situation would be pure torture for him. Whilst lacking the specificity that Baker J required of the patient's wishes in $W v M$, in Sheffield Hayden J said that TH has 'in so many oblique and tangential ways over so many years communicated his views so uncompromisingly, and indeed bluntly, that none of his friends are left in any doubt what he would want in his present situation' (para 53). The judge noted that the court had heard 'a holistic account of a man's character, life, talents and priorities' and that 'privacy, personal autonomy and dignity have not only been features of TH's life, they have been the creed by which he has lived it' (para 53, our italics). As such, it was in his best interests to go home and end his life quietly 
and with dignity. The judge reiterated the importance of Baroness Hale's judgment in Aintree in placing emphasis on a 'holistic' evaluation when assessing both 'wishes and feelings' and 'best interests', rather than focussing on individual sentences or remarks.

The religious views and practices of the patient are important evidence of the patient's narrative up to the point of incapacity and judges have attached significance to a patient's religious views in determining current best interests. In NHS Trust $v$ L [2013] EWHC 4313 (Fam), one of the factors in the balance sheet pointing towards the provision of active resuscitation was listed as the 'dignity in prolonging life, promoting personal autonomy and respecting an individual's religious principles' (para 121). Similarly in St George's NHS Foundation Trust $v$ P [2015] EWCOP 42, evidence from a cousin that the patient was a deeply religious man, who strongly believed that life was sacred, given by God and only taken away by God, was acknowledged in the balance sheet. In Newcastle upon Tyne NHS Foundation Trust v LM [2014] EWHC 454 (COP), Peter Jackson J went as far as stating that the wishes and feelings and long-standing beliefs and values of the patient in respect of blood transfusions, congruent with her beliefs as a Jehovah's Witness and evidenced in letters from members of her congregation, carried "determinative weight".

More recently, in $M v N$, Bury Clinical Commissioning Group [2015] EWCOP $76(\operatorname{Re} N)$ Hayden $\mathrm{J}$ considered a broad canvass of evidence to inform his decision whether it was in the patient's best interests to continue to receive artificial nutrition and hydration by way of the PEG tube. He observed that,

an assessment of P's wishes, views and attitudes are not to be confined within the narrow parameters of what P may have said. Strong feelings are often expressed non- 
verbally, sometimes in contradistinction to what is actually said. Evaluating the wider canvass may involve deriving an understanding of P's views from what he may have done in the past in circumstances which may cast light on the strength of his views on the contemplated treatment.

Wye Valley NHS Trust $v$ B [2015] EWCOP 60, affirmed the importance of adopting a 'holistic' approach on a case-by-case basis. Mr B at 73 years needed surgery for a leg amputation which the Trust believed was in his best interests (or he would die in a very short space of time); with surgery he might survive another few years. He had lived with a mental illness for many years, one of the symptoms of which was 'angelic voices'; he was refusing the surgery and was assessed as lacking the capacity to make the decision. Peter Jackson $\mathbf{J}$ stated that the weight given to wishes and feelings, beliefs and values of a person lacking capacity varies depending on the case but that religiously-based wishes and feelings such as B's should not be disregarded because they were long standing and integral to his life. B made statements consistent with his refusal: he believed that the amputation would be against God's will. The judge concluded: 'I am quite sure that it would not be in Mr B's best interests to take away his little remaining independence and dignity to replace it with a future which he understandably has no appetite and which could only be achieved after a traumatic and uncertain struggle that he and no-one else would have to endure' (para 45).

Section 4 of the MCA requires that the person making a determination about best interests must consider all the 'relevant circumstances' (ss2) of which he is aware and which are reasonable to regard as relevant (ss11). What we can see from recent court decisions is that the way a person has lived their life - what we could describe as their narrative up and 
beyond (as in Wye Valley) the point of incapacity - seems increasingly to have legal relevance in the determination of current best interests.

\section{Evidencing narrative and the weight attributed to it}

Narrative may be a useful way of seeing the different elements of relatives' and carers' testimony and past expressions of wishes, feelings, beliefs and values of a patient, drawing them together into a more compelling testimony that can have evidential weight in the process of best interests decision-making. It might thus provide a grounding and give weight to wishes and feelings that may have been informally but consistently expressed in the past. In $\operatorname{Re} N$ (2015) the Official Solicitor propounded that the strong element of substituted judgment in best interests' assessment is achieved through evidence from relatives about the patient's wishes and feelings which may assist the decision maker to understand the patient. But to what extent can narrative be evidenced and what weight is and should be attributed to it?

The difficulty of extrapolating current best interests from prior experiences and expressions was recognised in $R e N$. Hayden $\mathrm{J}$ questioned how the family's evidence of the patient's 'feistiness' translated into what she would want now (para 59) but ultimately, regarded the clear and compelling impression of Mrs $\mathrm{N}$, derived from evidence of her family as 'part of a picture which helps me to understand Mrs. N's moral imperatives and the code by which she lived her life' (para 59). N's family were able to give the patient a 'clear voice' in the courtroom, but how much more compelling and cogent were their views than those of the family of M, where Baker J did not give them substantial weight? 
In Re $M$ the patient's sister recounted that on visiting their grandmother in a nursing home $\mathrm{M}$ had said that, if she was in danger of going into residential home, she would rather shorten her life by ten years than have someone look after her (para 107). In $\operatorname{Re} N$ the daughter gave evidence that $\mathrm{N}$ hated seeing her parents in a diminished state living in a care home and recalled her mother saying "if I ever get like that shoot me!" (para 55). Evidence that the patients would not want to be a burden was also similar. M's sister recounted that $\mathrm{M}$ was fiercely independent and would have hated to be looked after. Hayden $\mathrm{J}$ in $\operatorname{Re} N$ went as far as stating that 'the importance of the wishes and feelings of an incapacitated adult, communicated to the court via family or friends but with similar cogency and authenticity, are to be afforded no less significance than those of the capacitous' (para32) and that where the wishes views and feelings of the patient can be ascertained with 'reasonable confidence', they are always to be afforded great respect.

How much weight should be attributed to factors such as 'independence', 'feistiness', 'courage', 'determination', and a 'dislike of intrusion into personal space' when assessing current best interests of the patient which may result in withdrawal of life sustaining treatment? The answer is likely to be that it depends on the context and the holistic assessment of a patient's narrative. When referring to wishes and feelings, in $I T W v \mathrm{Z}$ and others [2009] EWHC 2525 (Fam) Munby J concluded:

...one cannot as it were attribute any particular a priori weight or importance to P's wishes and feelings...and even if one is dealing with a particular individual, the weight to be attached to their wishes and feelings must depend upon the particular context (para 35). 
However, in light of the United Nations Convention on the Rights of Persons with Disabilities (CRPD), merely taking account of the patient's previously expressed wishes and her known beliefs and values would not go far enough. In contrast to competent adult decision making, where autonomous decisions are accorded respect, a person who lacks capacity (to make healthcare decisions) has decisions made for her, by the consultant in charge of her care, or the courts. Article 12 (4) requires States parties to adopt safeguards ensuring measures relating to the exercise of legal capacity that respect the rights, will and preferences of the person and the UN Disability Committee has interpreted this as indicating that 'national laws should provide support to disabled people to ensure that their will and preferences are respected, rather than overruled by action which is considered to be in the person's objective best interests' (Committee on the Rights of Person with Disabilities, 2014, paras 20 and 21).

As part of the post legislative scrutiny of the Mental Capacity Act 2005 evidence was given to the House of Lords Select Committee that placing greater emphasis on the role of the patient in the best interests decision making process both simultaneously diminishes the importance of objective criteria and achieves a closer alignment with the requirements of the CRPD, as the will, rights and preferences of the patient should be 'the starting point for any kind of determination of what is best for an individual' (paragraph 99). Bartlett goes further and suggests that if the ethos of Article 12 is to be implemented it would seem that a legislative amendment will be required in this respect' (Bartlett, 2012, p. 766). The Essex Autonomy Project position paper, Achieving CRPD Compliance (2014), recommends that;

The best-interests decision-making framework on which the MCA relies should be amended to establish a rebuttable presumption that, when a decision must be made on 
behalf of a person lacking in mental capacity, and the wishes of that person can be reasonably ascertained, the best-interests decision-maker shall make the decision that accords with those wishes.

In the consultation paper Mental Capacity and Deprivation of Liberty, (No. 222, 2015) the Law Commission was concerned that 'that the law currently fails to give sufficient certainty for best interests' decision-makers on how much emphasis should be given to the person's wishes and feelings' (para 12.42). It provisionally proposed that section 4 of the Mental Capacity Act should be amended so that there is an assumption that the person's wishes and feelings are 'determinative' as to their best interests, although the Commission noted that this assumption could be overridden where there are 'good reasons' to do so. Peter Jackson J in Wye Valley NHS Trust $v B(2015)$ commented that rather than leading to greater certainty such change would give rise to debate about whether there was or was not 'good reason' for a departure from the assumption and he considered that 'all that is needed to protect the rights of the individual is to properly apply the Act as it stands' (para 17).

However, the House of Lords Select Committee post legislative scrutiny of the Mental Capacity Act (2014) found that in many cases the statutory provisions for determining best interests, especially those concerning the wishes and beliefs of the patient, and consultation with family and carers, were 'not well known or used' (para 91).

\section{Implications for clinical practice}

In clinical practice healthcare professionals are tasked with providing 'objective' reasons for their determination of a person's best interests; they must be able to demonstrate them and show that they have considered all relevant circumstances and applied all elements of the best 
interests' checklist (MCA Code of Practice para 5.61). How healthcare professionals currently incorporate patients' wishes, feelings, values and beliefs in best interests' assessments requires more empirical research; undertaking this task may be straightforward in many instances, but fraught with problems in others.

Valid advance decisions provide health care professionals with some type of objective evidence of what the patient wishes and advance statements can provide more contextual information directly from that patient. Appointing a Lasting Power of Attorney can now formally recognise a patient's choice of decision maker in the best interests' assessment. However, currently only a minority of people use these legal means of expressing their wishes when they lack capacity. A recent survey (Dying Matters 2014 http://www.comres.co.uk/poll/1173/ncpc-dying-matters-survey.htm) reported that only $6 \%$ of British adults have written down their wishes/preferences for future care when they lack capacity and only $21 \%$ say that they have discussed their end of life wishes with somebody.

Given this, it is hardly surprising that best interests are often interpreted in a narrow - clinical - sense; healthcare professionals' expertise is in this area and they are likely to feel more assured in their decision-making in this respect, particularly when the stakes are high. The rhetoric around evidence-based (objective) medicine sits more comfortably in the context of assessing the clinical harms and benefits associated with particular treatments or procedures. This is something they can know and provide evidence for rather than something they might consider to be subjective or unreliable. Moreover subjective assessments might lead to more disagreement amongst healthcare professionals: in Wye, Dr Glover, a psychiatrist, stated that a body of his peers would probably splinter widely in their views on best interests of the 
patient and so would feel 'more comfortable morally' in opting to support the continuation of life.

Drawing on the accounts of those concerned with the welfare of the patient presents additional problems. Ho acknowledges that family and clinicians may appear to speak different languages when considering what is best for their loved one/patient and that there persists a credibility gap between the value attributed to medical 'facts' and family's 'views' in advocating for what they believe the person would have wanted (Ho 2009 p. 498). She argues that, especially when family members disagree with clinical recommendations, they can be labelled as too emotional to see the picture objectively: perhaps 'not getting it' or are 'in denial' or are suspected of having ulterior motives in advocating care options that appear counter to the patient's clinical best interests.

We are not advocating that clinical best interests be relegated in some way. Though an important part of best interests' decision making, the patient's views, wishes, beliefs and prior statements should not be seen as determinative either. Further, we should be cautious about the extent that family and friends really 'know' what the patient would have wanted or would want (see for example Shalowitz et al). Overreliance on the family's evidence of what the patient would have wanted in the current situation may also serve to marginalise health care professionals' view of the clinical benefits and burdens of treatment. For example, in NHS Trust v L [2013] EWHC 4313 (Fam) the patient's wife said that her husband had been a deeply religious man who had spoken of desiring a 'good death in line with his faith'. The family confidently believed that if Mr L could express himself, he would want to be given all possible treatment which would or might prolong his life. The view of the healthcare professionals in contrast was that 'unnaturally prolonging Mr L's life by invasive ventilation 
or resuscitation would seem cruel' (para 25). The judge recognised that the family's views and their assessment of Mr L's likely views should not be substituted for the balancing exercise required by the Mental Capacity Act.

How then can healthcare professionals integrate a patient's narrative into the best interest assessment in a meaningful way? Dementia UK have advocated the use of Life Story Work whereby a person's life is collated into a Life Story Book to help health and social care professionals understand more about that person. The books represent the person's past and present narrative and can provide useful evidence for best interest assessments alongside the context for daily care. (https://www.dementiauk.org/for-healthcare-professionals/freeresources/life-story-work/). The King's Psychosocial Assessment and Communication Evaluation (K-PACE) (Higginson et al 2013) was developed to support psychosocial aspects of care of very ill patients on intensive care units, aiming to establish an early assessment of the patient and family circumstances beyond medical diagnosis. It includes a checklist for information about the patient's spiritual/religious beliefs and whether the patient had expressed any preferences for treatment/care. Greater emphasis on supporting the relatives of very sick patients and the patient's individual needs has resulted in beneficial outcomes. This type of tool, whilst not aimed at determining all the information that might illuminate who the patient is, serves to underscore and remind clinicians of the importance of a paying attention to wider aspects of ill patients and their families - to 'do right' by the patient.

Both these initiatives set out to understand who the patient was and is. Family members may elucidate whether the treatment option proposed fits with the patient's views in general and who she is, or, as Blustein puts it "how well a particular decision hangs together with elements of the formerly competent patient's identity-constituting narrative" (Blustein 1999 
p. 23). This is not to suggest that a prior narrative ought to have prescriptive force, overruling any contemporary expressions of wishes or preferences - if these can be given - or to set a person's future path in stone. Rather, a patient's narrative provides a backdrop or context within which healthcare decisions can be made, providing a rationale for making sense of what a person might have wanted in the situation. It is part of the totality of the whole evidence base available to clinicians allowing them to gain a more substantial insight into the person's character in a way that isolated instances of expressions of values and wishes do not. Individually, these expressions may not amount to much, but attending to narrative provides an evidence base that is greater than the sum of its parts, and accords the patient's life dignity and respect.

\section{Conclusion}

Peter Jackson $\mathrm{J}$ stated in Wye that 'a conclusion that a person lacks decision-making capacity is not an "off-switch" for his rights and freedoms... It is I think, important to ensure that people are not - by the very fact of their disability - deprived of the range of reasonable outcomes that are available to others' (paras 11,12). We have argued that the legal obligation of the decision-maker in determining the best interests of a patient who lacks capacity could be helpfully construed using the concept of a patient 'narrative', which purposefully draws together atomistic pieces of evidence and testimony into a more coherent picture of a patient. Regard to patient narrative is congruent with an ethical obligation to respect the dignity of the patient and is consistent with patient-centeredness. However, we wish to make a stronger claim that attending to patient narrative is a useful heuristic for clinicians. Rather than considering the teasing out of narrative as an additional burden, adding complexity to clinical practice, this can be viewed as supportive of, and integral to, decision-making, providing meaningful evidence of best interests for the clinician. Narrative is one type of evidence and, 
whilst it may not be overwhelming or prescriptive, is has a valuable part to play in best interests' assessments.

\section{Disclosure statement}

The authors acknowledge that they have no financial interest or will receive any financial benefit arising from the direct applications of their research.

\section{References}

Bartlett, P. 2012 The United Nations Convention on the Rights of Persons with Disabilities and Mental Health Law, 75(5) MLR 752-778

Blustein, J. 1999.Choosing for others as Continuing a Life Story: The problem of personal Identity Revisited. Journal of Law, Medicine and Ethics 27: 20 -31

Carel, H. 2012. Patient Voices: Illness and Epistemic Injustice. Available from: http://www.slideshare.net/kingsfund/havicarel [Accessed January 2016].

Charon, R., 2004. Narrative and Medicine. N Engl J Med 350:862-864

Coulter, A. Collins, A., 2011. Making Shared Decision-Making a reality - No decision about me, without me. The King's Fund, London

Dresser R.1995. Dworkin on Dementia: Elegant Theory, Questionable Policy . Hastings Centre Report. 25 (6): 32-38

Greenhalgh, T. Hurwitz, B., 1999. Why Study Narrative? BMJ 318(7175): 48-50

Higginson, I., Koffman, J., Hopkins, P., Prentice, W., Burman, R., Leonard, S., Rumble, C., Noble, J., Dampier, O., Burnal, W, Hall, S., Morgan, M. and Shipman, C., 2013. Development and evaluation of the feasibility and effects on staff, patients, and families of a new tool, the Psychosocial Assessment and Communication Evaluation (PACE), to improve 
communication and palliative care in intensive care and during clinical uncertainty. $B M C$ Medicine 11:213 London

Ho, A., 2009. 'They just don't get it!' When family disagrees with expert opinion. J Med Ethics 35:497-501

House of Lords Select Committee on the Mental Capacity Act 2005, Post legislative Scrutiny, (HL Paper 139) The Stationery Office, London, 2014

Kuczewski, M.,1999. Narrative Views of personal identity and Substituted Judgment in Surrogate Decision Making. Journal of Law, Medicine \& Ethics 27 (1):32-36

Martin, W., Michalowski, S. Jutten, T. Burch, M. Achieving CRPD Compliance, An Essex Autonomy Project Position paper, 2014 http://autonomy.essex.ac.uk/uncrpd-report

Law Commission, Mental Capacity and Deprivation of Liberty Consultation paper, No. 222, 2015, The Stationery Office London, UK

Mullock, A., 2013. Best interests and the sanctity of life after W v M. J Med Ethics 39(9):553-4

Radden, J. and Fordyce, J., 2006. Into the darkness: losing identity with dementia, in Dementia: mind, meaning and the person (ed. Hughes, J., Louw, S., Sabat, S., Oxford University Press, Oxford

Shalowitz DI, Garrett-Mayer E, Wendler D. (2006) The accuracy of surrogate decision makers: a systematic review. Arch of Intern Med. 166(5):493-7

Smith, S.W. 2012. End-of-Life Decisions in Medical Care, Cambridge University Press, Cambridge

Strawson G, 2004. Against Narrativity Ratio 17: 428-52

Teichert, D., 2004. Narrative Identity and the Self, in Hidden Resources, (ed. Zahavi, D). Imprint Academic, Exeter, UK

United Nations 'Convention for the Rights of Persons with Disabilities.' Available online: 
http://www.un.org/disabilities/convention/conventionfull.shtml (accessed 28.1.2016)

Woods A.2011. The limits of narrative: provocations for the medical humanities. Medical humanities 37 (2): 73-78 